\title{
Archiving and Film Restoration: The View from Asia
}

\section{Dina Iordanova}

https://doi.org/10.15664/fcj.v0i17.2067

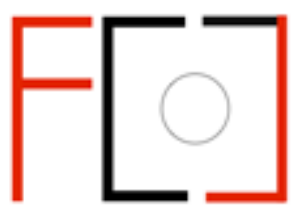

Frames Cinema Journal

ISSN 2053-8812

Issue 17 (Jun 2020)

(c) (i)

http://www.framescinemajournal.com 


\section{Archiving and Film Restoration: The View from Asia Dina Iordanova}

In the summer of 2019, I spent a few days at an international symposium of people involved with film preservation and archives at Xiamen University in China. ${ }^{1}$ The Chinese colleagues had brought important speakers from the USA, such as Jan-Christopher Horak, Dan Streible, and others. More importantly, however, they had agreed to feature a parallel programme of screenings dedicated to archival findings and restored films, as well as to take us on a visit to their new campus, where they held the materials of a large regional film archive.

It was during this event that the idea for the current dossier came about, informed by several factors: we heard presentations by several Chinese visual anthropologists and non-professional film collectors who sought to rescue, restore and archive "orphaned" material in places like Guangdong, Yunnan, and Gansu. We had the chance to view a selection of the material contained in the piled unprocessed holdings of the Fujian archive that the University had received from various sources and was working toward organising and restoring. Then, we attended screenings of several newly released Asian classics and heard the presentations of local archivists who told the complex stories of these restorations.

Each talk I listened to displayed two specific features: first, it revealed how the finding, evaluating, rescuing, restoring and archiving of lost Asian classics can meaningfully take place only in the context of well-intended transnational collaboration and with the good will and professionalism of archivists and cinephiles from different countries, small and large. It also made me realise how important it is that the discovery and presentation of this material is led by the people to whom it matters most: archivists and film historians from the respective Asian film cultures.

In initiating and commissioning work toward this dossier, these were also the criteria: I wanted to encourage writing that would foreground the transnational dimension of restoration work and to give opportunity to specialists who work in Asia to speak about it. I am pleased to say that each one of the pieces we include here shows quite naturally the importance of transnational collaborations for the restoration of Asian classics, and each one is authored by a colleague working in the respective source country. 


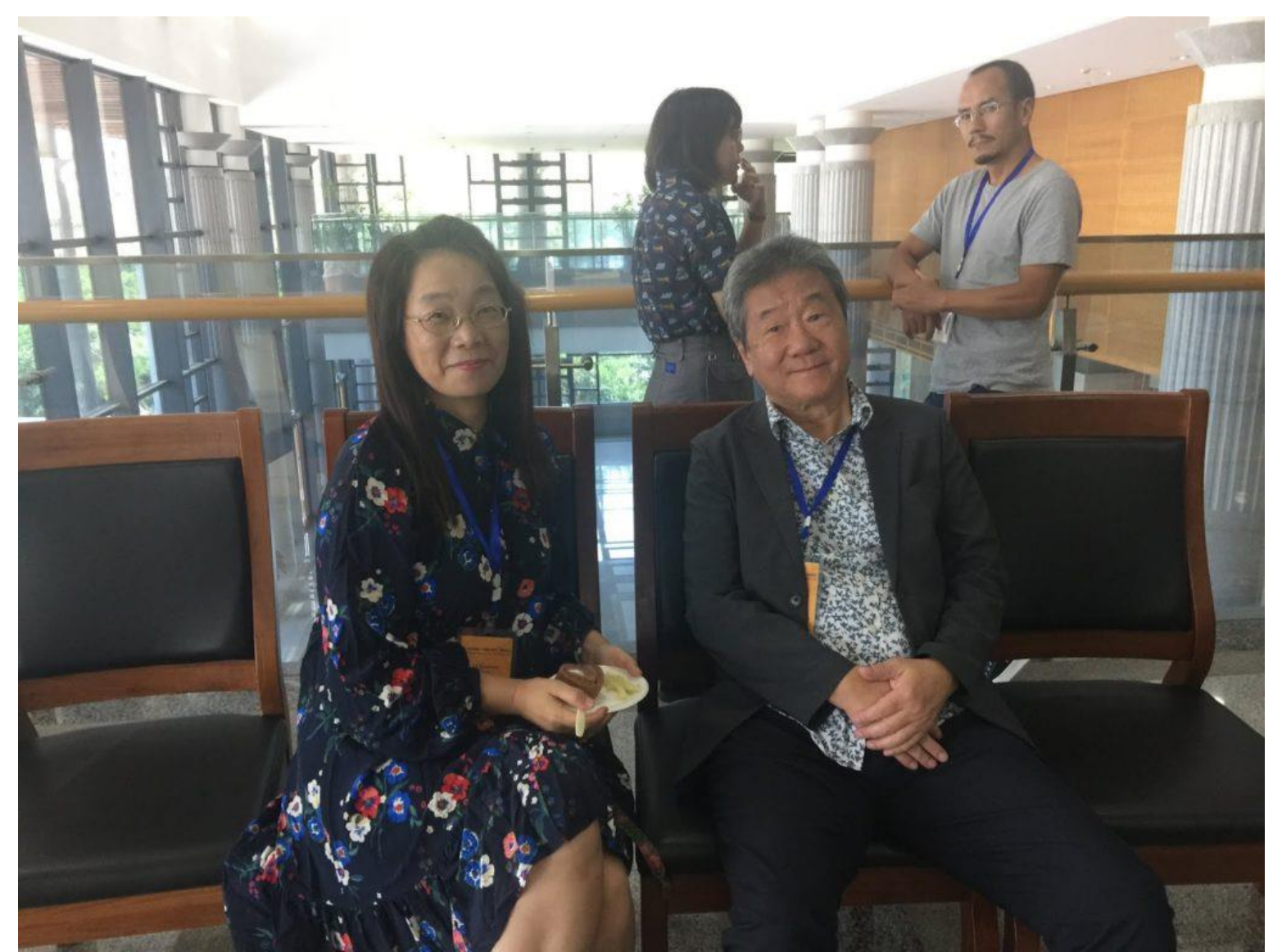

Figure 1: The Film Archives Symposium at Xiamen University in China, 2019: Prof. Li Xiaohong (Xiamen U) and Prof. Ray Jiing (Taiwan Film Collectors Museum)

\section{Film Restoration as Noble-minded Transnational Collaboration}

Some years back, colleagues from Filmarchiv Austria sent me a folder that contained about fifty still photographs from films that they thought were Bulgarian; they asked me to help them identify what was what. I could recognise and name some, but not all. I then sent the unidentified stills to more knowledgeable friends in Sofia, as well as directing some of the photos to people in Zagreb and Athens; what I saw made me suspect that these were stills from Yugoslav and Greek films rather than Bulgarian. Typically, I was acting in a noble-minded way, assisting a transnational project that was for the common preservation of our shared heritage.

Indeed, in the context of the Balkans, archivists in Vienna specifically have helped enormously with locating and restoring films, like in the case of the oldest Serbian feature The Life and Deeds of the Immortal Leader Karađorđe / Život i dela besmrtnog vožda Karađorđa (1911, Ilija Stanojević; which can be viewed at https://www.youtube.com/watch?v=rtoFKSA-Iak). Widely believed lost, it was found in 2003 in Austria and subsequently restored. ${ }^{2}$

And so it is with many other noble-minded collaborations. The discovery of the 1926 Chinese classic film The Cave of the Silken Web (Dan Du Yu) at a small library near the Arctic Circle in Norway in 2012 was another such story that made headlines (https://www.youtube.com/watch? ${ }_{\mathrm{v}}={ }_{\mathrm{O}}$ VO6iJQ-a8w). The film had been thought lost, and if it were not for the Norwegian discovery and the willingness to return the copy to China, it would still be listed as no longer available. 
More and more I realised the great extent that restoration and preservation work depends on the participation of an archival community beyond the specific countries where the material originates from.

It is the same story, of supportive international collaborations, that is revealed over again in the contributions to this dossier. They all report on exciting discoveries, repatriation, and restoration efforts that involve professionals and organisations based in more than one country. It is often the presence of an Asian researcher in the context of Western archives - which hold valuable material but do not know how to make sense of it - that has made all the difference (this is the case in the stories told here by Sanchai Chotirossearnee and Nick Deocampo). Archivists joining forces help to link up the dots and put together a film history that may have been patchy and incomplete.

In the case of Thai Santi-Vina (1954, Marut), for example, Thai researchers provided the proactive force behind the discovery, but the film could not have been found or restored without assistance from Gosfilmofond in Russia, the China Film Archive in Beijing, the BFI in the UK and Cineteca di Bologna in Italy. In the case of Singaporean They Call Her... Cleopatra Wong (George Richardson, 1978), as Karen Chan reports here, the collaboration extended to archives in Denmark and Austria, and the restoration was done in Portugal.

For this dossier, I made it a priority to commission writing that would reflect the excitement with which Asian researchers experience these discoveries and transnational restorations: interviews with Bede Cheng from L'Immagine Ritrovata in Hong Kong and with Quezon-city-based film historian Nick Deocampo from the Philippines, as well as reports of two specific case studies of discovery and restoration: Thai Santi-Vina (1954, available https://www.youtube.com/watch?v=VsDCxfSDgds) and Singaporean Ring of Fury (1973, available https://www.youtube.com/watch?v $=y 8 Q O P m I k 8 t Q)$. All the pieces in the dossier reveal restoration efforts that are proactively led by Asian researchers, who collaborate within a diverse multi-national and multi-directional network, as well as restoration assistance coming from various corners of the Arab world and Asia. ${ }^{3}$ 


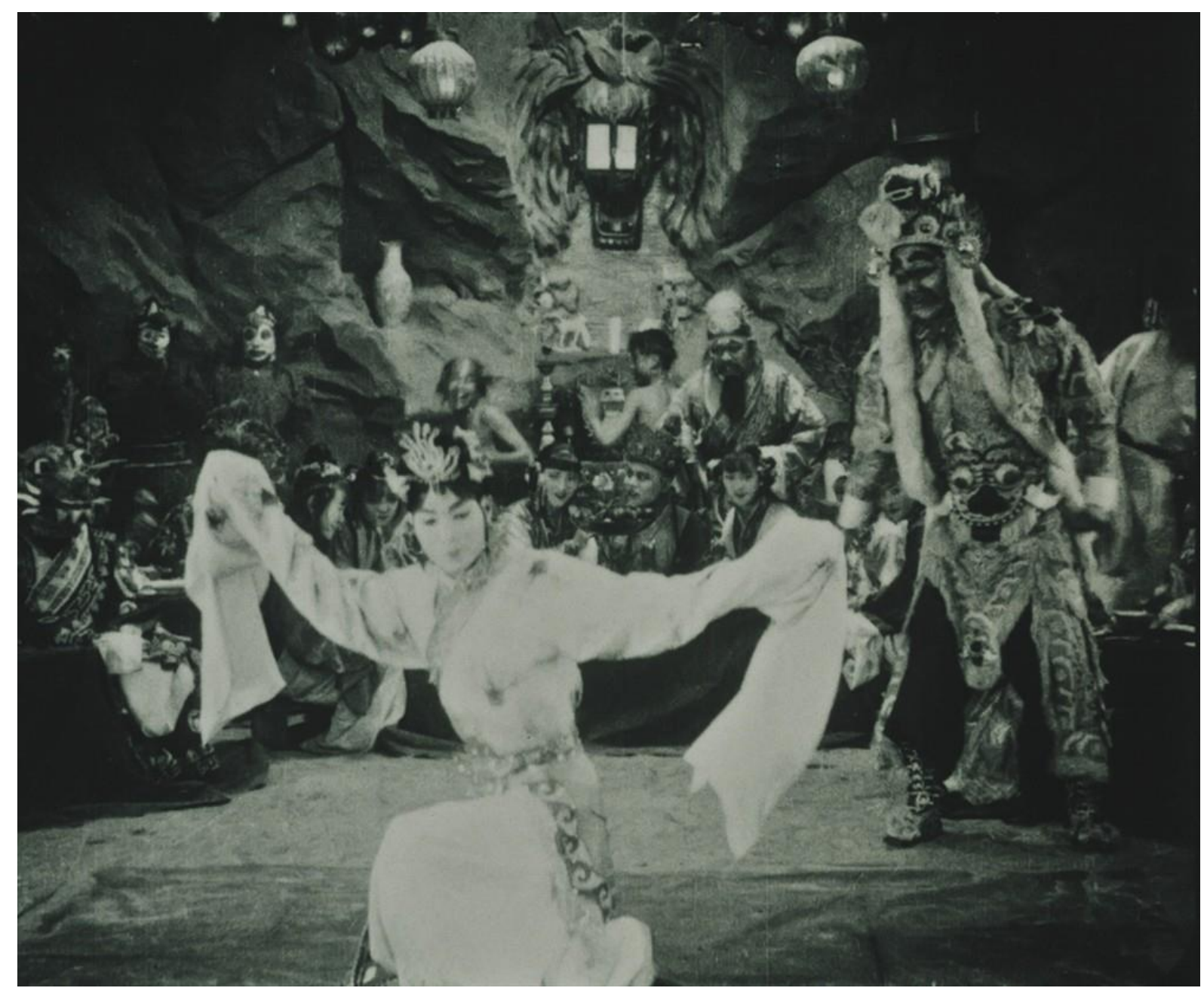

Figure 2: The lost Chinese classic The Cave of the Silken Web (1926) was accidentally found in 2013 at a provincial archive near the Arctic Circle, Mo i Rana in Norway.

\section{For a Comprehensive View of Film Culture's Places and People}

In the context of my work, I keep hearing of the work of various organisations and archives, mainly places such as the BFI, the Cinematheque Francaise, the Cineteca di Bologna, the Library of Congress, of film institutes and collections in Copenhagen, Oslo, Berlin, Vienna... The intention of this dossier is to ensure that lesser-mentioned archives come to the fore: The Asian Film Archive in Singapore, Gosfilmofond in Moscow, the China Film Archive in Beijing, the Thai Film Archive in Bangkok and the Hong Kong Film Archive... Some other important Asian archives are not explicitly mentioned here - such as the Korean Film Archive (https://eng.koreafilm.or.kr/main) - but it was the formidable work done by these organisations that drove me to seek to commission the contributions of the dossier. (I spoke briefly about my visits to some of these Asian archives in a piece for the IAMHIST blog). ${ }^{4}$

I also keep hearing of restored films from the Global South that premiered and were acclaimed at high profile showcases such as Cannes or Venice IFF, at specialised festivals such as Cinema Ritrovato in Bologna and the festival of silent cinema in Pordenone, or at places such as MoMA in NYC or at EYE Filmmuseum, Amsterdam. The wide coverage for such cinematic events leaves the impression that most Asian (or other films from smaller nations) are restored for the sake of being showcased at these festivals and that it is only these events that have the respective audience 
in place to see and appreciate such restored treasures. There is rarely mention of Asian events such as Memory! in Yangoon or the screening series at the Asia in Hong Kong - where restored works are screened and that are marked by the same cinephile dynamics that one discovers in Bologna and Pordenone. It seems important to bring these players into the picture. On my travels in Asia, I have had the chance to see the restored version of Lino Brocka's Manila in the Claws of Light (1975) at the Busan IFF in South Korea, the restoration of Story of a Discharged Prisoner (Hong Kong, 1967, Patrick Lung Kong) at Tai Kwun, and early gems by versatile experimental filmmaker Toshio Matsumoto at the Yamagata International Documentary Film Festival in Japan. So, I have come to believe that it is particularly important to keep track of the transcontinental dynamics in the circulation of these films, which spans far wider than often acknowledged.

The work we did in recent years toward exploring the global dynamics of festival constellations has profoundly changed the picture. ${ }^{5}$ Our evolving scholarship on the institutions of international film culture produces recorded evidence, aimed at correcting the view that archiving and restoring world cinema was and remains a Western project.

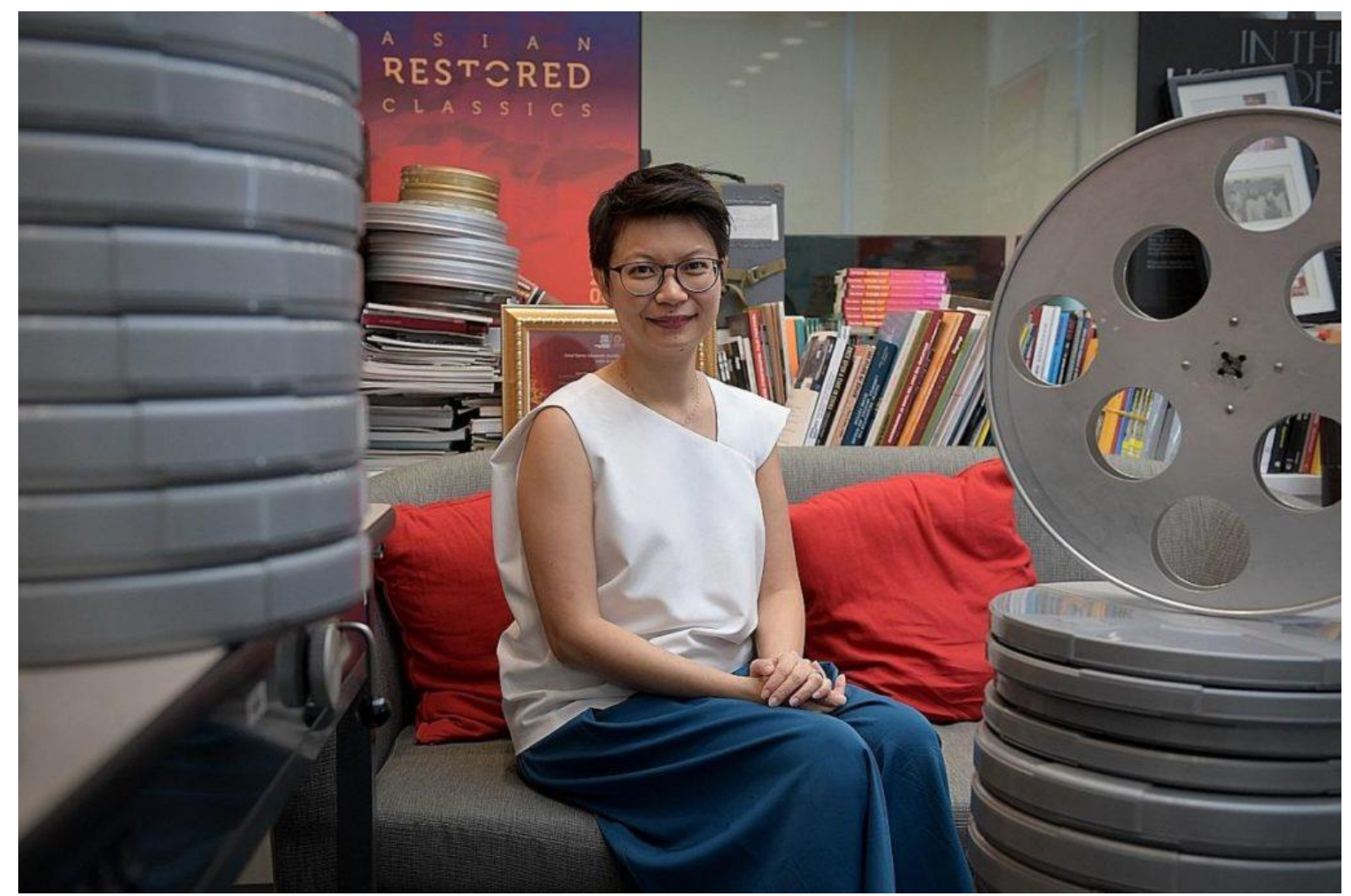

Figure 3: Karen Chan, Executive Director, Asian Film Archive, Singapore: The archivist can also be an Asian woman.

Similarly, in journal articles, conference presentations and doctoral dissertations I keep coming across mentions of the work of Western intermediaries who have contributed greatly to discovering, restoring and showcasing unseen cinema from various corners of the world: Gianluca Farinelli, Kevin Brownlow, Ian Christie, David Robinson, Peter von Bagh, Bernard Eisenschitz... The names of Dome Sukvong, Li Xun, Naum Kleiman, Ray Jiing, Aboubakar Sanogo, Soyoung Kim, Chalida Uabumrungjit, Karen Chan, Aruna Vasudev, Jak Shalom come up only occasionally in such listings. However - as I hope this dossier will reiterate - there is a thriving and dynamic 
community of archivists and restoration specialists who lead projects in collaboration with Western counterparts. It was with the intention that we hear some of the voices of these archivists and scholars that I commissioned this dossier.

One inspiring example of an attempt to restore the balance is found in Shivendra Singh Dungarpur's film Celluloid Man (India, 2016), featuring the life work of dedicated veteran archivist P. K. Nair (1933-2016) in Pune at India's National Film School Archive. I use it as one of the key films with the international constellations of postgraduates in my Film Cultures class. ${ }^{6}$

It is my hope that, in time, we will see a transformed frame of reference that will be more inclusive and that will list all these places and people next to one another, in recognising everybody's contribution.

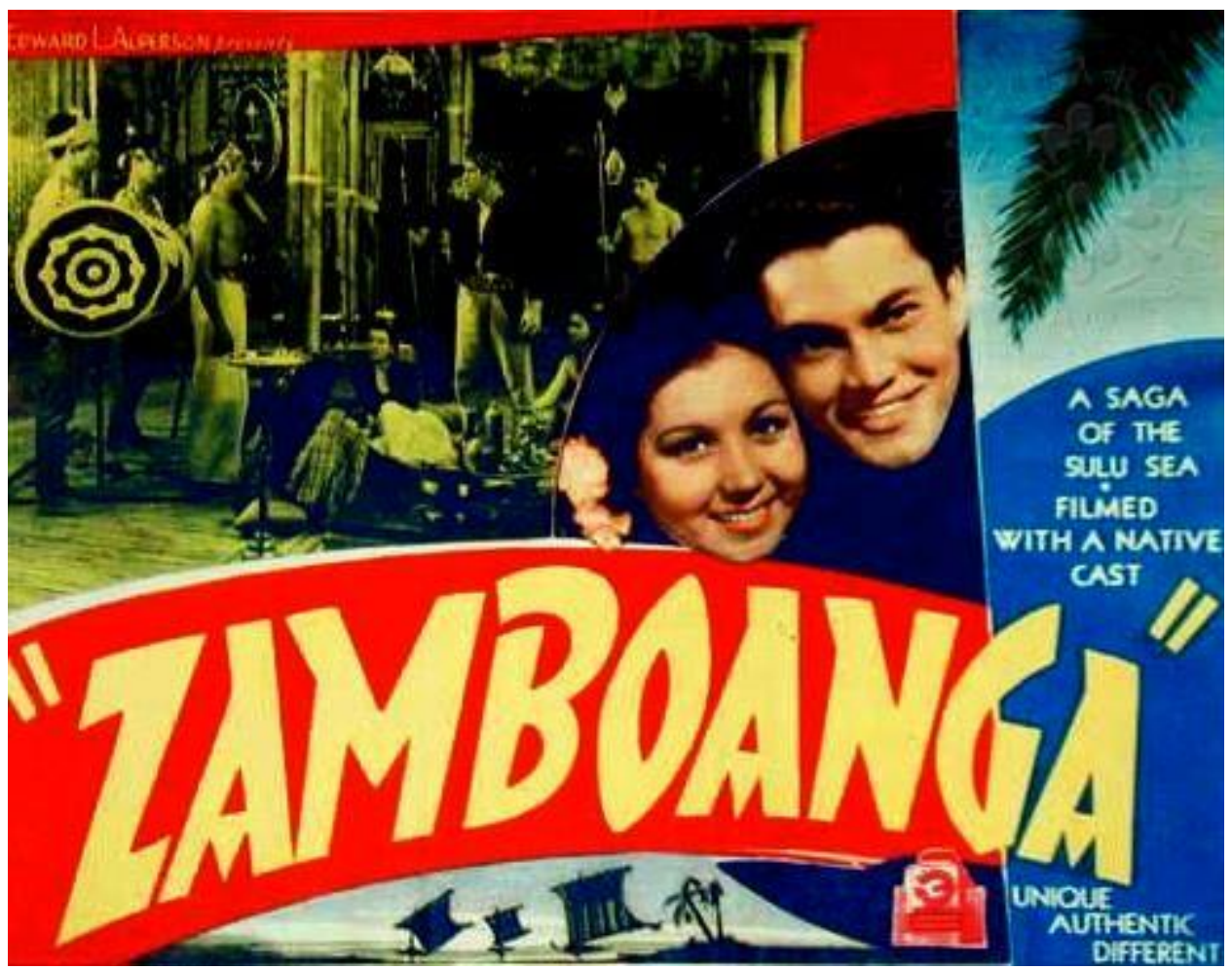

Figure 4: In his interview, Nick Deocampo describes the enthusiasm of discovering the lost Filipino classic Zamboanga (1937, Eduardo De Castro) at The Library of Congress. The film can be viewed at: https://www.youtube.com/watch?v=EWb6fo8ZbYI

\footnotetext{
${ }^{1}$ On the event, see NYU Dan Streible’s report, "Orphan films, Xiamen University”, https://wp.nyu.edu/orphanfilm/2019/07/25/xiamenu/
}

\footnotetext{
${ }^{2}$ In searching for the film, the transnational element was prevalent - even if the search was led by two researchers from Belgrade. First, it was established that its cinematographer, Louis de Beéry, was Hungarian rather than French, which helped reorient the search from France into the lands of former Austria-Hungary. The actual print of the film had sat for many years in the cellar of exhibitor Ignaz Reinthaler of Osijek (then in Austria-Hungary, today in Croatia), whose Austrian heirs had deposited it along with other old cans of film at the archive in Vienna. The University of St Andrews's doctoral alumna Ana Grgic has written about this discovery in her thesis on Early Balkan Cinema, forthcoming as monograph from Amsterdam University Press.
} 


\begin{abstract}
${ }^{3}$ A number of international classics in recent years have been restored with funds from the Doha Film Foundation. Even if Qatar itself does not have much of cinematic heritage of its own, it supports archival efforts of other countries in the region such as Turkey or Algeria. The Doha Film Foundation, thus, sets an example of a transnational cinema circulation in action, by supporting the restoration of non-Western films of global importance. They have funded the restoration of Bengali classic Titas Ekti Nadir Naam / A River Called Titas (India, 1973, Ritwik Gatahk), Indonesian Lewat Djam Malam / After the Curfew (1954, Usmar Ismail), Senegalese Borom Sarret (1963, Ousmane Sembene), Iranian Ragbar / Downpour (1971, Bahram Beyzaie), Lino Brocka's Maynila Sa Mga Kuko Ng Liwanag / Manila in the Claws of Light (Philippines, 1975), and Sri Lankan Nidhanaya / The Treasure (1973, Lester James Peries). Additionally, Qatar Airways have assisted, in partnerships, with funding for the restoration of El Hal / Trances (Morocco/France, 1981, Ahmed El-Maanouni), Hanyeo / The Housemaid (South Korea, 1960, Kim KiYoung), and Egyptian Shakavi El Flash El Fasi / The Eloquent Peasant and Al Momia / The Night of Counting the Years (both 1969, Shadi Abdel Salam). I am grateful to Andrea Gelardi for making available a comprehensive table that provided information on multiple internationally supported film restorations; this listing is extracted from it (2020).

${ }^{4}$ Iordanova, Dina. "Asian Archives and Archivists: Travels and Revelations”, LAMHIST Blog, 5 May 2020, Available: http://iamhist.net/2020/05/asian-archives-archivists-travels-revelations/ (Accessed: 23 May 2020).

${ }^{5}$ The leading editorial principle behind Alex Marlow-Mann's collection Archival Film Festivals (Film Festival Yearbook 5; St Andrews Film Studies, 2013) was similarly motivated by the desire to show the expansive transnational dynamics of this work; the volume includes pieces about the work of archivists and festival showcases for archival material in places like Russia, Thailand, Japan, Chile, etc.
\end{abstract}

${ }^{6}$ I also like to use Kuhu Tanvir's article that highlights the need to acknowledge the diversity within archives even further: "Pirate Histories: Rethinking the Indian Film Archive", BioScope: South Asian Film Cultures, Vol 4, Issue 2 (2013), 115-136.

\title{
About the Author
}

Dina Iordanova is Professor of Global Cinema and Creative Cultures at the University of St Andrews. She is interested in the transnational dynamics of film culture, as found in important transmission nodes such as film festivals, archives and museums. Entering the field as an East Europeanist, in recent years she has done extensive work with various Asian film festivals and various other cultural institutions in China, Hong Kong, South Korea, Japan and elsewhere. 